\title{
O nó da avaliação em ciências: Formando, deformando ou conformando?
}

\section{RESUMO}

Lucilene Aparecida e Lima do Nascimento

lucilene.nascimento@gmail.com

0000-0002-6963-0567

Instituto Federal de Educação, Ciência e Tecnologia do Rio de Janeiro, Nilópolis,

Rio de Janeiro, Brasil

\section{Giselle Rôças}

giselle.rocas@ifri.edu.br

nstituto Federal de Educação, Ciência

Tecnologia do Rio de Janeiro, Nilópolis,

Rio de Janeiro, Brasil
Este estudo refere-se a uma pesquisa desenvolvida com normalistas numa escola na Baixada Fluminense, no Rio de Janeiro. A partir do questionamento sobre as práticas avaliativas no Ensino de Ciências, buscou-se compreender a concepção de avaliação das participantes da pesquisa por meio de questionários e entrevistas, elementos utilizados como instrumentos de coleta de dados. Esta pesquisa traz uma abordagem qualitativa da análise desses dados, assumindo a pesquisa-ação como o fio condutor da metodologia. A análise evidencia o nó na avaliação do ensino de ciências e busca despertar a conscientização, reflexão e ação dos professores, pesquisadores da área e todos os que acreditam que é possível melhorar o ensino em ciências a partir da formação inicial de professoras em nível Médio, de forma a combater a deformação e/ou conformação para desatar esse nó.

PALAVRAS-CHAVE: Avaliação. Ensino em ciências. Formação de professores. Portfólio de avaliação. 


\section{INTRODUÇÃO}

O desafio de ensinar Ciências está - para além das preocupações das práticas pedagógicas - no zelo pela clareza e correção conceituais, de forma a aprimorar práticas investigativas e valorizar o conhecimento científico. A ciência moderna consolidou-se entre o final do século XVI e o início do XVII e foi fundamental para os processos civilizatórios, sendo "extremamente bem sucedida na explicação e previsão de fenômenos, assim como na criação de produtos tecnológicos" (MORAIS e ANDRADE, 2009, p.9).

Sendo assim, é muito comum que as explicações científicas sejam consideradas inquestionáveis. O que foi "cientificamente comprovado" passa a ser considerado verdadeiro e incontestável. Morais e Andrade $(2009$, p.9) afirmam "ser muito frequente a concepção de que a ciência é o modo, por excelência, de conhecer a verdade". $O$ entendimento neste estudo é que o professor da área de ciências deve compreender que mesmo

as mais atuais e sofisticadas teorias científicas são provisórias e sujeitas à revisão. [...] Na história da ciência, vários modelos e teorias foram construídos e considerados adequados para explicar fenômenos e processos. Trabalhos posteriores mostraram o caráter provisório dessas explicações, modificando ou mesmo condenando as ideias anteriores, ou reconhecendo sua validade para uma menor gama de fenômenos e processos e propondo modelos e teorias mais adequados e/ou mais amplos (MORAIS e ANDRADE, 2009, p. 11).

Outro aspecto abordado sobre o ensino de ciências, também pouco presente nas discussões escolares, diz respeito à ciência sujeita a injunções sociais, políticas e econômicas que financiam e podem delinear o que a ciência investiga e quais resultados podem ou não ser divulgados. Desta forma, é possível que a ciência atenda interesses de grupos específicos, gerando benefícios coletivos ou particulares, desejáveis ou indesejáveis do ponto de vista ético e socioambiental (MORAIS e ANDRADE, 2009, p.12). Apesar de todo o exposto, a construção de conhecimentos científicos pelos alunos é extremamente importante, considerando que

Essa construção favorece uma melhor qualidade de vida, maior competência e maior capacidade crítica frente ao uso de produtos tecnológicos, participação informada em processos democráticos de tomada de decisão quanto a temas que envolvem a ciência e possível escolha de se dedicar à carreira científica (MORAIS e ANDRADE, 2009, p.12).

Pozo e Crespo (2009) também se debruçaram sobre o tema e questionaram como os alunos aprendem (ou não) a ciência que lhes é ensinada. O fracasso escolar na aprendizagem das ciências é visto como uma "crise na educação científica" deflagrada no desassossego e frustração docente ao comprovar o limitado sucesso do seu esforço. Os autores também se reportam à avaliação utilizada pelos professores ao afirmar que para tal comprovação

[...] basta observar o escasso peso das atitudes na avaliação, pelo menos explicitamente. O que geralmente se avalia é o conhecimento conceitual e, em menor medida, o procedimental, mas as atitudes dos alunos praticamente não são levadas em conta, talvez porque se encaixam mal no tradicional 
conhecimentos conceituais, ao ensino do corpus conceitual das disciplinas [...] (POZO e CRESPO, 2009, p. 29).

Destaca-se que o conhecimento conceitual, procedimental e atitudinal a que se refere Pozo e Crespo é também apontado por Zabala (1998) como "tipologia dos conteúdos". Seu estudo indica as características essenciais de cada tipologia e previne que, embora apresente uma análise diferenciada para cada tipo de conteúdo, existe o perigo de "compartimentar o que nunca se encontra de modo separado nas estruturas de conhecimento" (ZABALA, 1998, p. 39). O alerta contido na fala de Zabala diz respeito ao sentido das tipologias (conceitual, factual, procedimental e atitudinal) criadas para compreensão/execução dos processos cognitivos de aprendizagem para que estes ocorram de maneira mais integrada. Ou seja, só há sentido nesta estratégia de diferenciação utilizada pelo teórico se ela for pensada a partir da análise da aprendizagem, e não do ensino propriamente dito. A perspectiva construtivista, proposta no estudo, tem por base a integralização máxima dos conteúdos, de forma que "todo conteúdo, por mais específico que seja, sempre está associado e portanto será aprendido junto com conteúdos de outra natureza" (ZABALA, 1998, p.40). Nesse contexto de prática educativa, a concepção de avaliação remete a um todo indiferenciado, onde o aluno é o sujeito e a aprendizagem é o objeto do processo educativo (ZABALA, 1998, p.196).

Sob tal perspectiva, retomando o ensino de ciências, observa-se que a exigência socioeconômica da competência tecnológica nos últimos anos faz surgir uma então nova expressão entre os educadores das Ciências Naturais: a alfabetização científica. A nomenclatura nasce da relação ciência-sociedade e traz novas exigências ao aluno e ao processo de aprendizagem. Sendo assim, seria natural a consequente mudança de toda prática educativa escolar nesta área de ensino. Krasilchik (2000) destaca que esta demanda social, por exemplo, fortalece o movimento temático transversal adotado nos Parâmetros Curriculares Nacionais para o Ensino Médio (PCNEM), vinculando educação ambiental, saúde e educação sexual, por tradição escolar, às disciplinas científicas.

Diante do exposto, talvez a pergunta que nos permita esclarecer qual deve ser a prática avaliativa no ensino de ciências seja: por que avaliar? As muitas respostas possíveis a essa simples questão deflagram a complexidade do tema e limitam esta reflexão a marcos de referência coerentes e admitidos em nosso aporte teórico, bem como correspondem à própria prática metodológica emergente neste estudo.

Zabala (1998) reporta-se criticamente ao tema, registrando que a tradição avaliadora está centrada exclusivamente nos resultados obtidos pelos alunos. 0 entendimento, neste caso, é que a avaliação não deveria estar a serviço dos seus resultados, antes o oposto. Luckesi (2002) dedica um capítulo do seu estudo para discorrer sobre uma avaliação que percebe o erro do aluno como fonte de virtude, desafiando seus leitores a fugir da lógica da avaliação que mede o quanto se aprendeu pela quantidade de acertos. Freire, em seus diversos estudos, classifica a concepção da "educação bancária", tornando o aluno um "depositário do saber", desembocando fatalmente numa "avaliação bancária" conforme análise de Romão (2002). O autor corrobora sua linha teórica apresentando a avaliação sendo dialógica, como um momento de aprendizagem e como um processo de mútua educação. Com olhar desviado, Hadji (2001) concentra-se na figura do avaliador, destacando que, devido à importância da dimensão social da avaliação, se faz necessário "libertar-se da alegoria da medida" e cita uma infinidade de exemplos 
em seu estudo sobre a "variação de medidas ou notas" dos corretores de um mesmo trabalho.

O fracasso escolar se apresenta, então, como um nó que não desata. Gonzaga, et al. (2013) afirma em seus estudos que a educação brasileira não se desenvolve de forma produtiva há muitos anos. Há décadas, vários estudiosos preocupam-se com a questão do fracasso escolar. O tema está indissociável à temática da avaliação, visto que é por meio de processos avaliativos que resultados são sistematizados e identificados como expoentes de sucesso ou insucesso escolar. Fica explícito que a avaliação em ciências deve ser objeto de reflexão e análise. A atual demanda de um conhecimento científico aplicado e contextualizado vai exigir uma avaliação integrada, onde o seu processo contemple não apenas resultados, mas também se estabeleça como um potencial instrumento de aprendizagem. Soares (1997) destaca que a escola tem se mostrado incompetente para educar, gerando o fracasso escolar e legitimando as desigualdades sociais. Em estudos posteriores Soares (2004) menciona que a preocupação brasileira antes estava concentrada ao fracasso escolar na alfabetização, mas hoje já se expande até o nível Médio. De forma mais pontual, Esteban (2001) aponta que a avaliação está profundamente marcada pela ótica da homogeneidade, igualando o ato de avaliar ao de julgar. Apresenta, então, em seus apontamentos, como possível solução, uma avaliação como um processo que deixa de ser "produtor do fracasso" para ser "articulador do sucesso escolar". De forma veemente, a pesquisadora acusa a escola de "subalternizar o conhecimento" para manutenção do fracasso escolar:

\footnotetext{
O estudo do fracasso mostra-se fecundo para entender como os processos postos à margem na escola, por serem destituídos de valor, podem se articular ao movimento de produção de formas subalternas de pensar, adquirindo novos sentidos e valores. [...] A manutenção do fracasso escolar dá indícios do entrelaçamento da constituição da escola e de suas práticas com os processos que originam e sustentam a colonialidade do poder, pois legitimar a subalternização do conhecimento é uma de suas condições (ESTEBAN, 2009, p.128).
}

A avaliação, quando não reduzida a momentos fragmentados do processo ensino aprendizagem, reinscreve seu sentido no conjunto das práticas pedagógicas e como tema transdisciplinar. A avaliação articula sujeitos e contextos diversos, ultrapassa fronteiras e capta a dinâmica mais favorável ao movimento de construção de conhecimentos (ESTEBAN, 2001), quando está a serviço da aprendizagem, conforme preconizado por Hadji (2001), e pode e deve ser um dos caminhos para a redução do fracasso escolar, ainda que este seja palco de infinitas definições e esteja circundado por aspectos do campo subjetivo.

Dessa forma, constatou-se no decorrer da pesquisa que ainda é comum, em pleno século XXI, encontrarmos no ensino de ciências no Ensino Médio, práticas avaliativas tradicionais, funcionando na base da memorização e "decoreba", fazendo o aluno protagonista de um processo educativo milenar que não lhe permite agir como ser pensante, criativo e crítico. No entanto, é também muito comum no meio docente um discurso afinado com as abordagens teóricas construtivistas $^{1}$ da avaliação. Percebeu-se, então, que o professor possui concepções avaliativas divergentes entre o seu discurso e sua prática.

Nesse ponto, é importante observar, na medida das nossas possibilidades e Página | 357 sem o risco de fugir da temática da avaliação, as peculiaridades do ensino de ciências, rastreando algumas tradições docentes da área, de forma a alterar 
profundamente práticas ritualísticas de avaliação, marcadamente de concepção tradicional, por novas práticas que assumam uma concepção avaliativa construtivista. Sobre a avaliação especificamente no ensino de ciências, percebese raras pesquisas, tornando este estudo relevante em sua temática sobretudo devido à escassez.

Este estudo é parte de uma dissertação que se propõe a compreender como ocorre a avaliação no ensino de ciências, e concentrou-se em descobrir qual a concepção de avaliação acolhida por alunas de duas turmas do 3o ano do Curso Normal numa escola estadual na Baixada Fluminense, no Rio de Janeiro. Ao desenvolver um portfólio de avaliação no ensino de ciências com um grupo de normalistas, buscou-se compreender qual o discurso assumido para práticas pedagógicas e avaliativas futuras. Em toda a extensão deste estudo, percorrendo o caminho metodológico da pesquisa-ação para além dos seus objetivos primeiros, buscou-se ainda despertar nas normalistas o interesse pela área de ciências. Para análise dos dados, optou-se por uma abordagem qualitativa, coletadas em questionários em formato quiz, bem como em entrevistas, constituindo-se no fio condutor reproduzido neste artigo.

O artigo se propõe ainda a trazer ao seu leitor a experiência instigante de uma análise qualitativa de dados que evidenciam problemas que tangenciam a avaliação. Nele são apresentados dados coletados na pesquisa desenvolvida, deflagrando na análise dos conteúdos dos discursos produzidos, nas concepções avaliativas controversas no ensino de ciências e ainda no papel da avaliação como dispositivo pedagógico essencial para compreensão do processo ensinoaprendizagem.

\section{O CURSO NORMAL - LOCAL DE FORMAÇÃO}

O Curso Normal no Estado do Rio de Janeiro, segundo o site da Secretaria de Educação do Estado do Rio de Janeiro (SEEDUC/RJ), ainda tem procura expressiva na rede de ensino. Ofertado em nível Médio, os dados mais recentes que datam de 2011 apresentam cerca de 40 mil alunos cursando esta modalidade em todo o Estado, distribuídos por 96 escolas. A modalidade, que tem por objetivo formar professores em nível Médio para atuar na Educação Infantil e nas séries iniciais do Ensino Fundamental (10 ao 5 ano), é cursada por três anos letivos em horário integral.

O Curso Normal, no Estado do Rio de Janeiro, passou por várias alterações nos últimos anos em sua estrutura curricular. Uma série de resoluções e portarias definem o contorno atual desta modalidade em nível Médio. Atualmente, a Matriz Curricular do Curso Normal é constituída pela base nacional comum, parte diversificada, formação profissional e práticas pedagógicas. A área de conhecimento "Ciências da Natureza, Matemática e suas Tecnologias", que abrange os componentes Biologia, Física, Matemática e Química, compõe a base nacional comum do Currículo.

As alterações na estrutura curricular do Curso Normal no estado do RJ nos últimos anos nos servem como fio condutor para o entendimento do quanto a formação de professores em nível Médio tem sido discutida e rediscutida nos 
em outubro/2013, quando comparada às matrizes anteriores, constata-se que pouca coisa mudou no âmbito das Ciências da Natureza e Matemática.

Leal (2013) discute em sua pesquisa o papel das Ciências da Natureza presente na Matriz Curricular do Curso Normal no RJ. A formação de professores na modalidade de Curso Normal em nível Médio, em 2010, passou a ter sua estrutura de funcionamento por três anos, em horário integral. Antes, o curso era desenvolvido por quatro anos letivos, em horário parcial. Sendo assim, até o ano de 2012, a Secretaria Estadual de Educação do Rio de Janeiro (SEEDUC/RJ) ainda continha, em seus quadros, turmas sob a égide da legislação anterior com quatro anos de Curso Normal, concomitante às novas turmas de três anos em horário integral. A autora alerta-nos para a importância dos documentos que norteavam o "conhecimento didático-pedagógico" dos futuros professores, com a clara intenção de "conceder qualidade na formação desses alunos-professores". Em ambas as matrizes curriculares, Leal (2013) destaca as horas totalizadas na Grade Curricular às Ciências da Natureza, sendo respectivamente para a matriz de quatro anos e de três anos, 400h e 480h. Ressalta-se que as matrizes curriculares apresentadas na sua pesquisa foram publicadas em 2010. Atualizando tal pesquisa, constata-se que, em 2012, a grade curricular separou Matemática de Ciências da Natureza, sendo 480h para Matemática e 480h para Ciências da Natureza distribuídas entre Biologia, Física e Química. A Matriz Curricular vigente, publicada em outubro/2013 (Resolução SEEDUC no 4951 de 04 de outubro de 2013 que fixa as matrizes curriculares da Educação Básica), mantém as 480h em Ciências acrescidas de mais $480 \mathrm{~h}$ de Matemática, que volta a fazer parte da mesma área de conhecimento na grade, denominada "Ciências da Natureza, Matemática e suas Tecnologias", perfazendo um total de $960 \mathrm{~h}$. Na prática, nada mudou. As alterações são essencialmente em juntar ou separar os componentes curriculares das Ciências Naturais à Matemática na disposição da Grade Curricular.

Quadro 1 Matriz Curricular Curso Normal em Nível Médio.

\begin{tabular}{|c|c|c|c|c|c|c|c|c|}
\hline \multirow{3}{*}{$\begin{array}{c}\text { Área de } \\
\text { Conhecimento }\end{array}$} & \multirow{3}{*}{$\begin{array}{l}\text { Componente } \\
\text { Curricular }\end{array}$} & \multicolumn{3}{|c|}{$\begin{array}{c}\text { Carga Horária } \\
\text { Semanal }\end{array}$} & \multicolumn{3}{|c|}{ Carga Horária Anual } & \multirow{3}{*}{$\begin{array}{l}\overline{\widetilde{T}} \\
\stackrel{0}{\circ} \\
\vdash\end{array}$} \\
\hline & & \multicolumn{3}{|c|}{ Séries } & \multicolumn{3}{|c|}{ Séries } & \\
\hline & & 10 & 20 & 3응 & 10 & 20 & 30 & \\
\hline Ciências da & Biologia & 2 & 2 & 0 & 80 & 80 & 0 & 160 \\
\hline Natureza, & Física & 2 & 0 & 2 & 80 & 0 & 80 & 160 \\
\hline Matemática e & Matemática & 4 & 4 & 4 & 160 & 160 & 160 & 480 \\
\hline suas & Química & 2 & 2 & 0 & 80 & 80 & 0 & 160 \\
\hline Tecnologias & TOTAL & 10 & 8 & 6 & 400 & 320 & 240 & 960 \\
\hline
\end{tabular}

Fonte: modificado do Anexo V da Resolução SEEDUC/RJ no 4951/2013 
Até 2012, o Curso Normal, tanto o de três anos como o de quatro anos, estava submetido à Reorientação Curricular (2006) específica para o Curso Normal, que buscava (re)orientar os procedimentos didáticos-metodológicos e avaliativos da modalidade. Em 2012, lançaram o Currículo Mínimo para o Ensino Fundamental e Ensino Médio Regular. Desde 2013, o currículo no Ensino Médio na Modalidade Normal é definido pelo Currículo Mínimo, disponível online para qualquer pessoa. Ao professor da rede estadual, ao identificar-se em aba específica, o acesso se expande para além do conteúdo do Currículo Mínimo de suas disciplinas. O site disponibiliza, em área reservada, material pedagógico exclusivo para cada disciplina, desmembrado por ano (1으 ao 30 ano do Curso Normal Nível Médio) e por bimestre, com orientações, recursos digitais, itens de avaliação, roteiros de aulas e material para Formação Continuada e orientações, tais como:

\footnotetext{
Prezado Professor, Desde 2012, a SEEDUC vem oferecendo mais uma ferramenta importante para auxiliar no seu planejamento escolar. O Currículo Mínimo serve como referência a todas as nossas escolas, apresentando as competências e habilidades básicas que devem estar contidas nos planos de curso e nas aulas. Sua finalidade é orientar, de forma clara e objetiva, os itens que não podem faltar no processo de ensino-aprendizagem, em cada disciplina, ano de escolaridade e bimestre. Está disponível material para consulta das 12 disciplinas da base Nacional comum, além de Resolução de Problemas Matemáticos, Produção Textual, Conhecimentos Didáticos, Formação Complementar, Fundamentos da Educação, Laboratórios Pedagógicos, Parte Diversificada e Práticas Pedagógicas (Fonte: Site SEEDUC/RJ, S/D).
}

Considerando as especificidades próprias do Curso Normal, este estudo avançou no sentido de coletar dados por meio de questionários formatados como um quiz, elaboração de portfólios de avaliação no ensino de ciências e entrevistas. Segue, em seção posterior, a coletânea das análises realizadas.

\section{INSTRUMENTOS DE COLETA DE DADOS}

Assumindo este núcleo temático-estratégico da avaliação, este estudo norteou-se pela questão: como aproximar o discurso da avaliação construtivista a uma prática avaliativa integrada ao ensino de ciências de forma a contribuir com o processo ensino-aprendizagem? Identificou-se em análises prévias que, apesar de alguns docentes no âmbito da área de ensino de ciências assumirem um discurso construtivista, propunham práticas avaliativas pautadas na concepção tradicional, denotando um descolamento entre a teoria e a prática. A intenção na pesquisa foi aproximar "o pensar e o fazer", a partir da articulação do ensino e aprendizagem às práticas avaliativas.

A pesquisa foi desenvolvida no âmbito de uma escola pública estadual da Baixada Fluminense no Rio de Janeiro, denominada Colégio Estadual Arruda Negreiros (CEAN). Duas turmas do 3ㅇa ano do Curso Normal, no ano letivo de 2014, que aqui denominaremos Turma $X$ e Turma $Y$, foram participantes neste estudo. Como instrumento de coleta de dados utilizaram-se questionários em formato quiz (NASCIMENTO, 2015), entrevistas e uma questão aberta. Cabe esclarecer que o quiz e a questão aberta foram realizados com ambas as turmas e antes da proposta de elaboração de um portfólio de avaliação no ensino de ciências. A entrevista foi aplicada somente na Turma X, por ter sido selecionada para elaborar o portfólio de avaliação segundo critérios de frequência de alunos. A turma Y era muito faltosa 
ou chegavam frequentemente atrasados, o que prejudicaria o desenvolvimento das atividades elencadas para o portfólio.

Todos os instrumentos de coleta de dados - quiz, questão aberta e entrevistas - estão explicados a seguir e foram interpretados conforme os princípios metodológicos de organização de análise segundo Bardin (2011). Para o quiz, utilizado em ambas as turmas, consideramos uma abordagem quantitativa das respostas marcadas, relacionando-as à Unidade de Contexto (UC) que serviu para definir os temas que foram a base de compreensão da Unidade de Registro (UR) utilizadas nas análises seguintes. Para as entrevistas (somente turma X) e a questão aberta (ambas as turmas), consideramos (1) a presença (ou ausência) de um elemento categorizado como UR e (2) a frequência de aparição de determinado elemento.

\section{ANÁLISE DO QUIZ}

Para categorização dos dados, organizamos as respostas das dez questões do quiz pela quantidade de vezes que cada item foi selecionado por cada aluna. Foram reunidos 27 (vinte e sete) quiz respondidos, sendo 14 (quatorze) da Turma X e 13 (treze) da Turma Y. Identificamos cada pergunta como uma UC e definimos, a partir da frequência das respostas, os temas a serem considerados como UR.

O quiz trazia um enunciado para as normalistas antes das questões: "Qual a medida da sua avaliação? Como alunos, acumulamos na caminhada escolar uma 'vida' sendo avaliados por diversos professores. Este "jogo" foi elaborado especialmente para que você, aluno do último ano do Curso Normal, futuro professor, consiga identificar o perfil de avaliador que mais se aproxima da prática docente desenvolvida pelos seus professores durante todo o seu curso! E descubra, nessa atividade, qual tipo de avaliador você quer ser quando iniciar sua prática! Divirta-se!"

A intenção era que o quiz fosse menos formal, mais lúdico e motivador à reflexão da prática avaliativa, distanciando-se da formatação de um questionário. O primeiro passo nesta fase foi criar os perfis de avaliadores que se pretendeu elencar no quiz. Definimos dois perfis principais: o avaliador de concepção tradicional e o avaliador de concepção construtivista. Reconhecemos no perfil de concepção construtivista três paradigmas mais atuais e referendados nos aportes teóricos da pesquisa, a saber: avaliador formativo, avaliador mediador e o avaliador que integra avaliação ao processo ensino-aprendizagem. A avaliação numa abordagem formativa ganha espaço nos estudos de Perrenoud (1998) e Hadji (2001), numa perspectiva emancipatória, de forma que atenda ao seu propósito de melhorar a aprendizagem. A avaliação mediadora é um paradigma proposto por Hoffmann (2000) que compreende a ação avaliativa como uma das mediações para a reorganização do saber, propondo diálogo e acompanhamento por parte dos educadores. Por fim, a avaliação integrada ao processo ensinoaprendizagem é proposta por Hadji (2001), ainda que imersa no conceito da avaliação formativa, por Zabala (1998) e por Sacristán (2000).

Importa esclarecer que não houve aqui a intenção de hierarquização das concepções avaliativas, mas atender ao aspecto lúdico da proposta do quiz como 
opção mais dialógica, participativa, democrática, emancipatória e como uma perspectiva que se propõe a desconstruir os modelos clássicos da avaliação tradicional.

Desta forma, composto com dez questões, ainda mantínhamos cinco opções de respostas. As respostas constantes na letra $(A)$ referiam-se ao perfil tradicional de avaliação. As letras (B), (C) e (D) continham respostas para um perfil de concepção construtivista da avaliação, sendo respectivamente o avaliador formativo, o avaliador mediador e o avaliador que integra avaliação e aprendizagem. Por fim, a letra (E), que sempre trazia escrito "outros" e uma linha para que o participante pudesse se expressar por escrito, caso nenhuma das questões atendesse plenamente sua resposta. O resultado buscava "encaixar o jogador" na resposta que mais vezes ele se enquadrava.

Observamos nos 27 quiz aplicados que, em nenhuma de cada uma das dez questões, a opção (E) foi assinalada. Optou-se excluí-la na versão seguinte. Para análise desses quiz, desconsideramos para composição dos percentuais a valoração da questão $(E)$, pois a sua frequência zerada $100 \%$ das vezes em que aparecia, deu-nos a clara percepção de que as opções elencadas nas letras (A), (B), (C) e (D) eram suficientes para responder a cada questão.

Seguem dois quadros, o primeiro com as perguntas e o segundo com os resultados da frequência percentual das respostas do quiz e suas respectivas análises.

Quadro 3 Perguntas Quiz - Versão Preliminar de 10 questões.

\begin{tabular}{|l|l|}
\hline 01 & $\begin{array}{l}\text { Na sua opinião, qual o propósito dos seus professores ao avaliar você } \\
\text { através do instrumento "prova"? }\end{array}$ \\
\hline 02 & $\begin{array}{l}\text { Considere seus professores autônomos completamente para escolher os } \\
\text { instrumentos de avaliação de aprendizagem em um bimestre letivo. } \\
\text { Qual o grupo de instrumentos avaliativos eles mais fizeram uso durante } \\
\text { o seu curso? }\end{array}$ \\
\hline 03 & $\begin{array}{l}\text { Em que momento os professores costumam realizar a avaliação dos } \\
\text { alunos? }\end{array}$ \\
\hline 04 & $\begin{array}{l}\text { Considere os conteúdos conceituais das disciplinas da área de Ciências } \\
\text { Naturais (Biologia, Química e Física). Como seus professores costumam } \\
\text { prepará-los para avaliação dos mesmos? }\end{array}$ \\
\hline 05 & $\begin{array}{l}\text { Qual a frase abaixo que, na sua opinião, define um bom aluno no } \\
\text { conceito de seus professores: }\end{array}$ \\
\hline 06 & $\begin{array}{l}\text { Considerando as disciplinas das áreas de Ciências, quais os enunciados } \\
\text { que você mais costuma encontrar nas propostas avaliativas: }\end{array}$ \\
\hline 07 & Qual perfil de escola que mais lhe agrada? \\
\hline 08 & $\begin{array}{l}\text { Nas aulas-passeio (atividades culturais) a qual avaliação você é } \\
\text { submetido? }\end{array}$ \\
\hline 09 & Como você acredita que o professor interpreta o seu erro? \\
\hline 10 & Qual o foco da avaliação de seus professores nas áreas de Ciências? \\
\hline
\end{tabular}


Numa análise primeira dos resultados e olhando de forma global, as respostas voltadas para a concepção tradicional de avaliação foram as mais selecionadas entre as opções, remetendo os autores ao questionamento: estamos formando ou deformando as futuras professoras? No entanto, em busca de um refinamento desta análise, cada pergunta foi analisada segundo o percentual das opções disponíveis.

Quadro 4 Frequência Percentual de Respostas do Quiz.

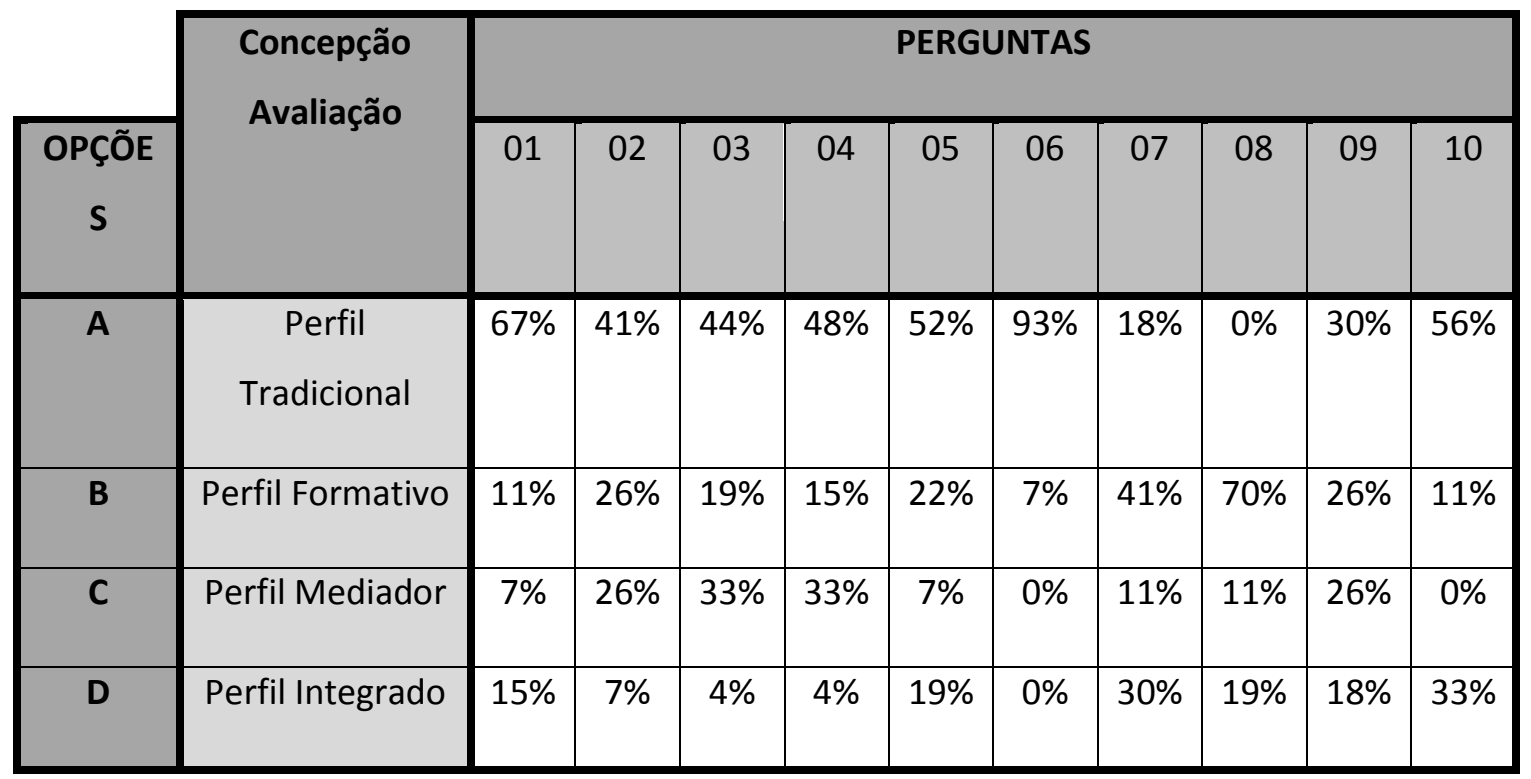

Fonte: Arquivo próprio, elaboração própria

Pergunta 01: Na sua opinião, qual o propósito dos seus professores ao avaliar você através do instrumento "prova"? - Em uma conversa informal com a Coordenadora Pedagógica do CEAN questionou-se o porquê da escola agendar em seu calendário uma semana letiva destinada às provas, visto que alguns professores não utilizam este instrumento de avaliação. Ela explicou que esta semana deveria constar em relatório enviado à Coordenadoria Regional da SEEDUC/RJ, e que entre os itens constantes neste documento segue um calendário bimestral com esta semana definida pela Unidade Escolar, que deve anteceder os dias determinados pela Secretaria de Educação para conselhos de classe. Acrescentou ainda que os professores que não faziam uso de tal instrumento deveriam destinar essa semana às avaliações na disciplina. A compreensão de que a avaliação se resume a um ato docente a cada final de período bimestral é recorrente e compõe facilmente o cenário do senso comum sobre a questão. Romão (2002) atenta para este fato em seu estudo e afirma que a compreensão de que a avaliação deve ocorrer "especialmente nos momentos de terminalidade" é um importante aspecto da concepção da função classificatória da avaliação. $O$ alto percentual para a resposta da opção $(A)$ - "Medir a quantidade assimilada e a não assimilada de conteúdo, para expressar em notas ou conceitos" - corrobora como a maioria das 27 alunas percebem a prova como um mero instrumento de medida a ser expresso em notas. Analisando as respostas, não há como desconsiderar os $15 \%$ que identificam a prova como um instrumento autoavaliativo. Muito provavelmente, após conversar sobre as respostas com as 
turmas, este grupo menor compreende que a prova é também um instrumento em que elas mesmas podem medir o quanto estudaram ou ainda precisam estudar a disciplina. Embora a opção (D) do quiz - "Minha prova é construída com perguntas de autoavaliação para saber como o aluno se vê no processo ensinoaprendizagem" - buscasse compreender se algum professor lançava mão da autoavaliação como sugerida na Portaria 419/2013, o entendimento das alunas ao responder parece não corresponder à intenção da opção desta resposta. Ainda: $11 \%$ das alunas compreendem na opção (B) que a prova é um instrumento que o professor faz uso para coleta de dados sobre o que deve ser revisto no conteúdo programático. Por fim, $7 \%$ delas, na opção (C), acreditam que o professor faz uso da prova porque é obrigado pela instituição. Ao informá-las que nenhum dos professores é obrigado - nem pela SEEDUC/RJ, nem pela direção do CEAN - a utilizar prova como instrumento de avaliação, elas demonstraram perplexidade. Elas explicaram que pensavam que apenas as Disciplinas Pedagógicas, Educação Física e Artes, para elas do Curso Normal, estavam dispensadas dessa obrigação.

Pergunta 02: Considere seus professores autônomos completamente para escolher os instrumentos de avaliação de aprendizagem em um bimestre letivo. Qual o grupo de instrumentos avaliativos eles mais fizeram uso durante o seu curso? - Esta pergunta possui uma ausência grave em seu enunciado que pode ter influenciado as respostas, considerando o grupo a que se destina. Normalistas possuem uma carga horária integral e muitas disciplinas pedagógicas ao longo do curso. É muito mais comum neste grupo o uso constante de instrumentos avaliativos diversos, principalmente nas disciplinas específicas do curso, do que em qualquer outro curso profissionalizante de nível Médio. Dito isto, o resultado, mesmo comprometido pelo entendimento da maioria das alunas de que a pergunta referia-se a todas as disciplinas do curso (e não somente à Área das Ciências Naturais, Matemática e suas Tecnologias), cabe ressaltar que a análise se deu conforme o entendimento da questão. 41\% selecionou o grupo de instrumentos avaliativos próprios da concepção tradicional de avaliação, na opção (A). Há de se considerar que é um percentual significativo, uma vez que o grupo se tratava de futuros professores, o qual teoricamente tem acesso às mais novas e atualizadas concepções pedagógicas, modeladas pelo paradigma construtivista que preconiza a construção de saberes e o desenvolvimento de habilidades e competências. As respostas (B) e (C), com $26 \%$ cada, demonstra em seu conjunto (52\%) que, como é próprio no Curso Normal, o uso de instrumentos diversos para avaliação, mais próximos da concepção construtivista, são muito utilizados. Obtivemos ainda $7 \%$ que declaram que seus professores avaliam todo o processo na opção (D), tudo que é feito, realizado e construído em sala de aula, sem especificar os instrumentos utilizados.

Pergunta 03: Em que momento os professores costumam realizar a avaliação dos alunos? - Embora pareça que novamente a concepção tradicional da avaliação obteve o maior percentual nas respostas, se faz necessária a compreensão correta em cada uma das respostas. A compreensão de associar o final de cada bimestre letivo - quando o professor deve expressar em notas ou conceitos o desempenho de cada aluno - à necessidade de um período específico destinado às avaliações é fato, daí o percentual significativo na opção (A) que trazia como resposta "Ao final de cada bimestre". No entanto, observa-se que o discurso da avaliação contínua e processual é também muito comum na práxis dos docentes do Curso Normal no CEAN. São $56 \%$, totalizando as opções (B), (C) e (D), que traziam respostas de concepções construtivistas. Compreendemos que as respostas nas três opções 
afirmam a presença da característica processual na avaliação, onde o professor acredita em uma avaliação que se desenvolve ao longo da aprendizagem. Desta forma, a maioria (56\%) respondeu ser avaliada durante o período bimestral e $44 \%$ ao final de cada bimestre. Para compreender os significados das respostas, as alunas afirmaram em aulas sobre o processo avaliativo que, muitas vezes, os professores usam instrumentos diversos avaliativos durante o bimestre e, ao final do bimestre, aplicam uma prova. Talvez se justifique então o equilíbrio das respostas.

Pergunta 04: Considere os conteúdos conceituais das disciplinas da área de Ciências Naturais (Biologia, Química e Física). Como seus professores costumam prepará-los para avaliação dos mesmos? - A opção (A) trazia como resposta: "Memorizando os conceitos através de questionários pré-elaborados". A memorização é uma prática muito utilizada no universo escolar e apreciada por muitos docentes, pais e até alunos. A fixação metódica pela repetição sistematizada (decorar) costuma ser diferenciada por alguns da memorização. Nos blogs disponíveis para "concurseiros" habitualmente encontramos listas com técnicas de memorização e essa diferenciação entre memorizar e decorar é feita por alguns. Em síntese, eles afirmam que decorar significa reter na memória algo sem compreensão do seu significado e memorizar significa compreender e registrar na memória o conhecimento. Não sabemos ao certo a compreensão das normalistas sobre o termo "memorização", mas entendemos que, por senso comum, por constar nos dicionários "memorizar" e "decorar" como palavras sinônimas, que a interpretação da resposta (A) se deu dessa forma. Quando elaborada a opção de resposta (A), a intenção foi exatamente esta: a memorização como ato de fixação pela repetição. Dessa forma, o percentual muito próximo à metade das participantes, nos leva a perceber o quanto é usual a memorização por questionários como metodologia para preparar alunos nas disciplinas de Ciências. De acordo com Perrenoud (1998), esta prática é uma das características da concepção classificatória da avaliação, centrada nos resultados e nos registros quantitativos. Observamos ainda que $33 \%$ afirmam o papel mediador do professor entre o que o aluno compreende e o conceito formal do conteúdo aplicado, na opção (C).

Pergunta 05: Qual a frase abaixo que, na sua opinião, define um bom aluno no conceito de seus professores - Conceituar um aluno como "bom" é uma tarefa que exige a observância de vários aspectos. No entanto, as respostas das opções eram bem simplistas. Na opção (A) a resposta dizia que bom aluno seria "o que consegue na escala avaliativa o máximo conceito ou nota". É muito comum que o professor esteja condicionado a considerar como bom aluno os que apresentam melhor desempenho expresso em notas. No âmbito das escolas estaduais (RJ) em geral, onde a hierarquização das escolas define bonificação salarial, não é de se espantar que os docentes estejam ainda mais impregnados por essa lógica simplista. Parece óbvia a resposta de $52 \%$ das alunas replicarem essa lógica, não fossem os $48 \%$ que respondem nas opções (B), (C) e (D) que seus professores acham que bons alunos são os que aprendem para a vida, os que são capazes de conduzir a própria aprendizagem e os que conseguem relacionar o que aprendem ao seu cotidiano. Quase metade das alunas reconhecem nos seus professores, que estão submetidos à lógica perversa de hierarquização estatística da educação estadual no RJ, a capacidade de análise qualitativa dos alunos para os definirem como bons. 
Pergunta 06: Considerando as disciplinas das áreas de Ciências, quais os enunciados que você mais costuma encontrar nas propostas avaliativas - A utilização de enunciados que requer na maioria das vezes respostas prontas (objetivas) é quase de 100\%. Questões formuladas com enunciados próprios de uma avaliação tradicional nos mostra o quanto podemos ainda estar distantes da proposta construtivista de avaliação na área de Ciências. Por achar que esta questão estava muito semelhante à questão 2 , optamos por excluí-la do quiz.

Pergunta 07: Qual perfil de escola que mais Ihe agrada? - Esta questão, após análise cuidadosa, pareceu desnecessária ao propósito do quiz, e por este motivo foi excluída. Na realidade, a pretensão estava em conduzir o aluno a responder o perfil do corpo docente que mais lhe agradava. Em conversa informal com as alunas, descobrimos que suas respostas na realidade indicavam como elas gostariam que fosse o espaço escolar no CEAN. E as preferências da composição do espaço se divergem, mas demonstram o quanto a escola oferecida a elas está longe de suas expectativas. A ausência de plantas na escola, segundo elas, deixa o ambiente triste e muito "cinzento", explicando a escolha de 41\% pela opção (B) que traz uma escola com plantas. Com um laboratório de informática que elas afirmam nunca poderem usar e a ausência de outros espaços essenciais à formação, também foi apontado como grave problema, justificando as respostas (C) e (D), que juntas comportam também 41\%. Outra preocupação encontrada nas respostas relaciona-se ao entorno da escola, considerado perigoso, com assaltos diariamente, de forma que foi considerado natural que algumas alunas respondessem em $18 \%$, que prezam pela segurança do ambiente escolar na opção (A). Palma e Martins (2008) destacam a importância de se pensar nas mudanças que os tempos modernos impõem às escolas e acrescentam que tais mudanças devem ser culturais e estruturais, visto que "a arquitetura e a ocupação do espaço físico não são neutras" (PALMA e MARTINS, 2008, p.11)

Pergunta 08: Nas aulas-passeio (atividades culturais) a qual avaliação você é submetido? - Esta questão também foi excluída do quiz. Seu propósito inicial era conhecer como os docentes se portavam nas aulas-passeio das turmas e como utilizavam esta ferramenta no processo avaliativo. No entanto, foi constatado que o CEAN possui em seu corpo docente uma professora com profundo interesse nas aulas-passeio. Docente de Língua Portuguesa no Curso Normal, a professora costuma realizar anualmente várias saídas com os alunos. Esses eventos acontecem há anos com esta professora e não estão limitados às suas turmas. Todas as turmas do Curso Normal costumam ser convidadas e vão preenchendo as vagas de forma aleatória, conforme o interesse do aluno e sua disponibilidade na carga horária. Quanto aos seus alunos, a aula-passeio se transforma em um relatório a ser entregue, para "ajudar" na composição da nota do aluno participante. Compreendemos que a opção (B), por mencionar o relatório como instrumento avaliativo, representava bem esse contexto local, por isso $70 \%$ dos alunos a selecionaram.

Pergunta 09: Como você acredita que o professor interpreta o seu erro? - As opções de respostas escolhidas estão bem divididas. No entanto, o mais importante, é observar nesta questão que $70 \%$ dos alunos, ao optarem pelas respostas constantes nas opções (B), (C) e (D), não acreditam que seus professores interpretam seus erros como sinal de não apreensão do conteúdo. Sem ignorar os $30 \%$ que pensam exatamente o contrário e que optaram em dizer que o professor acredita que o erro significa que "o aluno não sabe o conteúdo" na opção $(A)$, o 
resultado é motivador. Dois terços dos alunos concluintes do Curso Normal em 2014 nesta escola entendem que seus professores interpretam seus erros com uma percepção ressignificada no contexto do processo educacional, buscando alternativas para conduzir a ação educativa. Nesse sentido, considerando o afastamento da "visão culposa do erro, na prática escolar" (LUCKESI, 2002, p.48), é possível afirmar que, nestas turmas do Curso Normal desta escola, não há conformação e menos ainda deformação do processo avaliativo quando se trata do erro do aluno.

Pergunta 10: Qual o foco da avaliação de seus professores nas áreas de Ciências? - O foco da avaliação, no ensino na Área de Ciências Naturais no Curso Normal nesta escola, aparenta ser sobre o desempenho dos alunos, meramente quantitativo, conforme opção (A). Mas o que dizer dos $44 \%$ que não consideram este o foco e responderam as opções (B), (C) e (D)? O que dizer dos $33 \%$ que afirmam na opção (D) que afirma que a avaliação em Ciências é sempre contínua e integrada? Intrigada com essa questão, algumas alunas foram questionadas sobre como elas gostariam de ser avaliadas. Solicitou-se responderem por escrito a seguinte pergunta: Como você gostaria de ser avaliado nas disciplinas da Área de Ciências (Biologia, Física, Química e Matemática)? Esta análise será descrita na próxima seção e esta pergunta será denominada neste estudo de "Questão Aberta".

\section{ANÁLISE DA QUESTÃO ABERTA}

Reunimos dezenove (19) respostas à Questão Aberta: "Como você gostaria de ser avaliado nas disciplinas da Área de Ciências (Biologia, Física, Química e Matemática)?". Foram nove alunas da Turma X e dez alunas da Turma Y.

Importa esclarecer que, conforme planejamento prévio da pesquisa, a Turma $X$ foi selecionada para elaborar os portfólios. No período que se propôs a Questão Aberta às turmas, a "Turma X" já estava elaborando os portfólios, participando das palestras e oficinas oferecidas à turma, discutindo amplamente o teor do processo avaliativo, bem como suas concepções. A "Turma Y" usufruía das aulas cotidianas, onde a pesquisadora abordava o tema avaliação dentro do contexto exigido pela disciplina que ministrava às alunas, sem participar da elaboração dos portfólios. Ressalta-se, ainda, que no dia em que as turmas responderam, a frequência foi prejudicada pelas condições climáticas.

Os discursos presentes nas respostas foi objeto de análise com base na categorização temática proposta por Bardin (2011). O tratamento do material em seu estado bruto foi o primeiro passo por meio de leitura e releitura dos dados. A correlação entre o aporte teórico, o objetivo da pesquisa e os dados coletados foi necessária para a categorização das Unidades de Registros (UR). A categorização iniciou-se a partir do isolamento dos elementos comuns (inventário), seguida da organização das mensagens (classificação). Para definir a grelha de categorias por temas nesta análise, utilizou-se do agrupamento de elementos (UR) por critério semântico e léxico (BARDIN, p.118).

O principal objetivo foi estabelecer como as alunas, que eram futuras professoras, desejavam ser avaliadas nas áreas de Ciências e Matemática, 
significativas para o entendimento da concepção avaliativa das alunas-professoras. Sintetizadas em categorias, as repostas foram analisadas e organizadas na tabela 1 para facilitação do entendimento. Consideramos para cada UR a frequência simples que infere valoração de igual importância de aparição do elemento.

Cruzando os dados entre os quiz e as respostas da Questão Aberta, observamos alguns fatores relevantes para esta pesquisa. Quando $56 \%$ das alunas no quiz respondem que o foco de avaliação dos seus professores, da área de Ciências, é uma avaliação centrada no conteúdo (Quadro 4, Coluna 10, Opção A), corroboram o discurso negativo de $42 \%$ ao conformismo do uso de instrumentos tradicionais de avaliação como provas, testes e questionários (Tabela 1). Ainda quanto a instrumentos de avaliação, no quiz encontramos que $41 \%$ do alunado afirmam que os professores utilizam preferencialmente provas e testes como instrumento de avaliação (Quadro 4, Coluna 2, opção A). Compreensível então que $42 \%$ das alunas (Tabela 1), na Questão Aberta, respondam livremente contrariedades em relação a esses instrumentos tradicionais de avaliação. Por fim, $53 \%$ ainda sugerem espontaneamente vários outros instrumentos avaliativos e também $52 \%$ indicam a participação do aluno como algo a ser levado em conta pelo professor na hora da avaliação (Tabela 1). 
Tabela 1 Categorias de Análise - Questão Aberta "Como você gostaria de ser avaliado nas disciplinas da Área de Ciências (Biologia, Física, Química e Matemática)?”

\begin{tabular}{|c|c|c|c|}
\hline Categoria & $\begin{array}{l}\text { Caracteres } \\
\text { comuns (UR) }\end{array}$ & Subcategoria & $\begin{array}{c}\% \\
\text { frequência } \\
\text { de } \\
\text { aparição }\end{array}$ \\
\hline Avaliação & $\begin{array}{l}\text { Contínua, } \\
\text { progressiva, feita } \\
\text { diariamente }\end{array}$ & $\begin{array}{c}\text { Concepção } \\
\text { construtivista da } \\
\text { avaliação }\end{array}$ & $37 \%$ \\
\hline $\begin{array}{c}\text { Negação da } \\
\text { avaliação que } \\
\text { acontece } \\
\text { (como não } \\
\text { gostaria de ser } \\
\text { avaliado) }\end{array}$ & $\begin{array}{c}\text { Não usar provas, } \\
\text { não usar testes, } \\
\text { não usar } \\
\text { questionários }\end{array}$ & $\begin{array}{c}\text { Não aos } \\
\text { instrumentos } \\
\text { tradicionais de } \\
\text { avaliação }\end{array}$ & $42 \%$ \\
\hline $\begin{array}{l}\text { Sugestões de } \\
\text { instrumentos } \\
\text { para uma } \\
\text { avaliação } \\
\text { diferenciada }\end{array}$ & $\begin{array}{l}\text { Vídeos, oficinas, } \\
\text { trabalhos de } \\
\text { pesquisa, } \\
\text { maquetes, aulas- } \\
\text { passeio, jogos, } \\
\text { dinâmicas, } \\
\text { ludicidade }\end{array}$ & $\begin{array}{c}\text { Novos instrumentos } \\
\text { de avaliação }\end{array}$ & $53 \%$ \\
\hline $\begin{array}{l}\text { A participação } \\
\text { do aluno em } \\
\text { sala de aula } \\
\text { como } \\
\text { instrumento de } \\
\text { avaliação }\end{array}$ & $\begin{array}{c}\text { Participação, } \\
\text { troca, aula } \\
\text { dinâmica, } \\
\text { colaborativa, } \\
\text { instrumentos } \\
\text { avaliativos }\end{array}$ & Aula participativa & $52 \%$ \\
\hline $\begin{array}{l}\text { Associação do } \\
\text { uso da teoria } \\
\text { como algo ruim } \\
\text { e da prática } \\
\text { como algo bom }\end{array}$ & $\begin{array}{c}\text { Injustiça x justiça } \\
\text { Dificultar x } \\
\text { facilitar } \\
\text { Só teoria x mais } \\
\text { prática }\end{array}$ & $\begin{array}{c}\text { Dicotomia Teoria e } \\
\text { Prática }\end{array}$ & $26 \%$ \\
\hline
\end{tabular}

Fonte: Arquivo próprio, elaboração própria

Mais uma observação interessante se destaca nesta tabela. O discurso de 37\% das alunas está impregnado de termos teóricos, próprios do meio docente como avaliação contínua, avaliação progressiva e instrumentos avaliativos. E ainda fazem menção à dicotomia teoria $x$ prática, afirmando nos discursos que a segunda se encontra ausente das estratégias de aula em detrimento da primeira. Embora ainda não estivessem formadas e nem na prática da profissão docente à época da coleta desses dados, as alunas normalistas já assumiram, em bom número, um discurso teórico de classe.

\section{ANÁLISE ENTREVISTAS}


Quanto às entrevistas, utilizou-se o mesmo procedimento metodológico de análise de dados da Questão Aberta. Nesta fase, apenas as alunas da Turma X, que já estavam elaborando o portfólio de avaliação, foram envolvidas. Por este motivo, o número de entrevistados é diferente do número de alunos que responderam ao quiz e à questão aberta. Inicialmente, foi elaborada uma sequência de perguntas a constar na entrevista.

Quadro 5 Perguntas pré-elaboradas para a entrevista.

\begin{tabular}{|l|l|}
\cline { 2 - 2 } \multicolumn{1}{c|}{} & Perguntas \\
\hline 1 & $\begin{array}{l}\text { Falando sobre avaliação da aprendizagem, você acha que alguma coisa } \\
\text { mudou no seu entendimento sobre o tema depois das nossas aulas? }\end{array}$ \\
\hline 2 & $\begin{array}{l}\text { O que achou da elaboração do Portfólio de Avaliação como instrumento } \\
\text { de avaliação? }\end{array}$ \\
\hline 3 & Quais os pontos positivos e negativos? \\
\hline 4 & $\begin{array}{l}\text { Como futura professora, qual prática avaliativa você quer adotar com } \\
\text { seus alunos? }\end{array}$ \\
\hline
\end{tabular}

Fonte: Arquivo próprio, elaboração própria

A entrevista foi realizada individualmente. Para fins de análise do conteúdo, após transcrição das entrevistas e o tratamento bruto dos discursos coletados, optou-se seguir a ordem das perguntas e a categorização do discurso das respostas em cada uma delas. Seguem os dados organizados em categorias nas tabelas abaixo, com suas subcategorias e o percentual de frequência de aparição dos caracteres comuns:

Tabela 2 Categorias de Análise Entrevista - pergunta 1: “Falando sobre avaliação da aprendizagem, você acha que alguma coisa mudou no seu entendimento sobre o tema depois das nossas aulas?"

\begin{tabular}{l|l|l|l}
\hline Categoria & Caracteres comuns (UR) & Subcategoria & $\begin{array}{l}\% \\
\text { frequência } \\
\text { de } \\
\text { aparição }\end{array}$ \\
\hline \hline Sim & $\begin{array}{l}\text { Sim, mudou, acho que } \\
\text { mudou, acredito que sim }\end{array}$ & $\begin{array}{l}\text { Visão sobre } \\
\text { avaliação } \\
\text { modificada }\end{array}$ & $100 \%$ \\
\hline Não & $\begin{array}{l}\text { Não há resposta não ou } \\
\text { negativa }\end{array}$ & $\begin{array}{l}\text { Ausência de } \\
\text { negativa }\end{array}$ & $100 \%$ \\
\hline anterior & $\begin{array}{l}\text { Prova, teste, trabalho, } \\
\text { avaliação no papel, } \\
\text { tradicional }\end{array}$ & $\begin{array}{l}\text { Avaliação } \\
\text { Tradicional }\end{array}$ & $64 \%$ \\
\hline Visão atual & $\begin{array}{l}\text { Agora entendo, outra } \\
\text { visão, entendo melhor }\end{array}$ & $\begin{array}{l}\text { Novo perfil de } \\
\text { avaliação } \\
\text { construído }\end{array}$ & $85 \%$ \\
\hline
\end{tabular}

Fonte: Arquivo próprio, elaboração própria 
No caso específico desta pergunta, observou-se um nervosismo exacerbado em cada uma das alunas. Embora elas tenham sido preparadas e tudo explicado em relação à entrevista, ser entrevistada pela própria professora-pesquisadora, ainda que esclarecido que esta atividade não fazia parte do processo avaliativo das disciplinas ministradas pela professora, elas se mostraram tímidas e apreensivas na primeira pergunta. Algumas comentaram posteriormente nunca terem sido entrevistadas e que a novidade daquela circunstância as deixou nervosas. No entanto, com o decorrer das perguntas, as alunas foram ficando mais à vontade, não invalidando os dados coletados. Desta forma, obter $100 \%$ de resposta positiva e nenhuma negativa à primeira pergunta pode ser em virtude do contexto explicitado anteriormente. Ainda assim, incentivadas a continuar a falar, $64 \%$ declararam que sua visão anterior sobre avaliação estava pautada em procedimentos tradicionais e $85 \%$ contaram sua nova percepção sobre avaliação de forma entusiasta, indicando que o trabalho desenvolvido despertou nelas este olhar, permitindo trazer a discussão sobre avaliação para o processo de formação. Fato este, percebido na fala de uma das alunas entrevistadas: "Mudou a questão da visão (sobre avaliação), não é somente teste e prova. Você pode usar outras formas de avaliar, usando outros instrumentos, outros mecanismos..."

Tabela 3 Categorias de Análise Entrevista - pergunta 2: “O que achou da elaboração do Portfólio de Avaliação como instrumento de avaliação?"

\begin{tabular}{c|c|c|c}
\hline Categoria & $\begin{array}{c}\text { Caracteres comuns } \\
\text { (UR) }\end{array}$ & Subcategoria & $\begin{array}{c}\% \\
\text { frequência } \\
\text { de } \\
\text { aparição }\end{array}$ \\
\hline \hline $\begin{array}{c}\text { Elaboração } \\
\text { como ação } \\
\text { positiva }\end{array}$ & $\begin{array}{c}\text { Bom, maravilhoso, } \\
\text { criativo, prático, } \\
\text { diferente, legal, } \\
\text { bacana }\end{array}$ & $\begin{array}{c}\text { Portfólio como bom } \\
\text { instrumento de avaliação }\end{array}$ & $85 \%$ \\
\hline $\begin{array}{c}\text { Elaboração } \\
\text { como ação } \\
\text { negativa }\end{array}$ & $\begin{array}{c}\text { Difícil compreensão } \\
\text { Parece um diário }\end{array}$ & $\begin{array}{c}\text { Portfólio como } \\
\text { instrumento de difícil } \\
\text { elaboração }\end{array}$ & $15 \%$ \\
\hline
\end{tabular}

Fonte: Arquivo próprio, elaboração própria

Nesta questão, a grande maioria acatou a elaboração do portfólio positivamente. Dos $15 \%$ que não aprovaram, uma aluna relatou sua dificuldade em compreender a estrutura de elaboração do portfólio e outra declarou achar parecido com um diário pessoal. 
Tabela 4 Categorias de Análise Entrevista - pergunta 3: “Quais os pontos positivos e negativos?"

\begin{tabular}{c|c|c|c}
\hline Categoria & Caracteres comuns (UR) & Subcategoria & $\begin{array}{c}\% \\
\text { frequência } \\
\text { de aparição }\end{array}$ \\
\hline \hline $\begin{array}{c}\text { Pontos } \\
\text { Positivos }\end{array}$ & $\begin{array}{c}\text { Mudou a rotina, } \\
\text { criatividade, redução de } \\
\text { sobrecarga }\end{array}$ & $\begin{array}{c}\text { Aplicabilidade e } \\
\text { compreensão }\end{array}$ & $72 \%$ \\
\hline $\begin{array}{c}\text { Pontos } \\
\text { (pregativença) }\end{array}$ & $\begin{array}{c}\text { Chato fazer, muito } \\
\text { trabalhoso }\end{array}$ & Sobrecarga & $21 \%$ \\
\hline $\begin{array}{c}\text { Pontos } \\
\text { (ausêtivos }\end{array}$ & $\begin{array}{r}\text { Não há pontos negativos, } \\
\text { não sei }\end{array}$ & - & $72 \%$ \\
\hline
\end{tabular}

Fonte: Arquivo próprio, elaboração própria

A intenção com essa questão era que todos fossem capazes de elencar os avanços e dificuldades da elaboração de um portfólio. Uma única aluna disse não saber responder sobre os pontos negativos. Outras três relataram as dificuldades de elaboração, de escrever e outras coisas. Mas a mesma proporção que afirmou não haver pontos negativos, elencou vários pontos positivos na elaboração do portfólio. Seguem alguns trechos marcantes dos relatos sobre o portfólio nas entrevistas que denotam a satisfação de algumas alunas com a elaboração realizada: Aluna 1 - "O portfólio? Achei interessante... querendo ou não acaba desenvolvendo o aluno... é ele que tem que buscar, pesquisar, participar...", Aluna 2 - "...explora a criatividade, faz com que o aluno lembre o que aprendeu...", Aluna 3 - "...um trabalho que vai ser a sua cara, do jeito que você pensa, o jeito que você age, ali construir uma coisa do seu jeito..." 
Tabela 5 Categorias de Análise Entrevista - pergunta 4: “Como futura professora, qual prática avaliativa você quer adotar com seus alunos?

\begin{tabular}{c|c|c|c}
\hline Categoria & Caracteres comuns (UR) & Subcategoria & $\begin{array}{c}\% \\
\text { frequência } \\
\text { de } \\
\text { aparição }\end{array}$ \\
\hline \hline $\begin{array}{c}\text { Instrumento } \\
\text { Tradicional de } \\
\text { avaliação }\end{array}$ & $\begin{array}{c}\text { Não pode deixar de dar } \\
\text { prova, não dar só prova }\end{array}$ & Provas, testes & $57 \%$ \\
\hline Portfólio & Usar o portfólio & $\begin{array}{c}\text { Portfólio de } \\
\text { Avaliação }\end{array}$ & $36 \%$ \\
\hline $\begin{array}{c}\text { Instrumentos } \\
\text { construtivistas } \\
\text { de avaliação }\end{array}$ & $\begin{array}{c}\text { Vídeos, teatros, aulas } \\
\text { passeio, palestras, atividades } \\
\text { lúdicas, participação do } \\
\text { aluno }\end{array}$ & $\begin{array}{c}\text { Atividades } \\
\text { diversificadas }\end{array}$ & $64 \%$ \\
\hline $\begin{array}{c}\text { Negação ao } \\
\text { instrumento } \\
\text { tradicional }\end{array}$ & Não darei prova & $\begin{array}{c}\text { Negação do uso } \\
\text { instrumento prova }\end{array}$ & $22 \%$ \\
\hline
\end{tabular}

Fonte: Arquivo próprio, elaboração própria

Nesta tabela percebemos que o grupo extrapolou as expectativas desta pesquisa-ação. Embora $57 \%$ reafirme a utilização de provas como um dos instrumentos avaliativos, $22 \%$ negam com veemência a utilização desse instrumento, $64 \%$ enumeram atividades avaliativas diversas e $36 \%$ citam o portfólio de avaliação, até então desconhecido por elas. Destaco que os instrumentos avaliativos reunidos na tabela 5 como atividades diversificadas, foram sugestões de avaliação propostas nas aulas para constar em um portfólio. Retoma-se o título do artigo, no qual está proposto uma provocação, identificando-se que elas não se conformaram com as diversas provas ou processos avaliativos tradicionais ao longo de seus percursos escolares.

Entende-se que esta análise de conteúdo das entrevistas (BARDIN, 2011) deve-se apoiar nos elementos constitutivos da figura do emissor (neste caso as alunas entrevistadas), do receptor (pesquisadoras - autoras) e da mensagem (o material - significantes e significados - coletados nos discursos). Os emissores, já contextualizados às concepções avaliativas estudadas durante todo o Curso Normal e mais especificamente com a professora-pesquisadora, declaram mudanças em suas concepções, mas também revelam por meio das suas mensagens submeterem-se à forte influência da lógica avaliativa tradicional, o que explica os $57 \%$ de alunas fazendo uso das provas para avaliar seus futuros alunos. Isso fica muito claro nos discursos reproduzidos pelas alunas do CEAN:

"Eu pretendo avaliar, não só com teste e prova...", “... usar a prova também porque eles têm que ser avaliados assim também, pra eles terem essa noção do que é uma prova...", "... também provas e tal, que acho importante ele passar aquilo pro papel, porque infelizmente nossa avaliação continua assim ainda, por exemplo, se no futuro ele quiser entrar numa faculdade? Ele ainda vai precisar disso né?" Estas falas primeiro demonstram a manutenção do instrumento prova nas avaliações dos supostos alunos das futuras professoras. Embora estivéssemos nos reportando aos alunos das séries iniciais, visto que esta é a formação de cada 
uma delas ao término de 2014, o futuro acadêmico desses alunos imaginários é utilizado como motivo para a continuidade do uso de instrumentos tradicionais de avaliação.

Por outro lado, os $36 \%$ que citaram o uso do Portfólio de Avaliação indicam que muitas ainda têm dúvidas relacionadas à aplicabilidade e compreensão do instrumento. Mesmo que tenham, cada uma individualmente, elaborado um portfólio de avaliação, e tenham indicado pontos positivos como a redução de sobrecarga, um instrumento autoavaliativo, algo novo e uma alternativa de avaliação, a maioria não se sentiu à vontade de cogitar fazer uso desse instrumento com seus alunos. Em contrapartida, todas as sugestões avaliativas utilizadas na turma durante as palestras, oficinas e aulas foram repetidas vezes citadas em seus discursos: "... elaboração de vídeos, peça teatral, debates, eu acho mais legal do que fazer essas coisas de só prova escrita mesmo...", "...de forma dinâmica, que tenha trabalhos, tenha atividades lúdicas...", "... vários trabalhos, tipo palestra e tal...", "... com atividades lúdicas, vídeo-aulas...". O que mostra que atividades diferenciadas e, por vezes, associadas a ludicidade, despertam o interesse dos alunos e favorecem a aprendizagem (MESSEDER e RÔÇAS, 2010; LEAL, 2013)

\section{ALGUMAS CONSIDERAÇÕES}

Com o objetivo principal de descobrir qual a concepção de avaliação acolhida por alunas do Curso Normal e compreender qual o discurso assumido para práticas pedagógicas e avaliativas futuras, constatou-se que os resultados obtidos alcançaram a proposta inicial do projeto de pesquisa, fato este percebido nos apontamentos descritos nas análises de cada instrumento de coleta de dados.

Na medida em que a pesquisa foi se desenvolvendo, alguns percalços foram surgindo. A dinâmica da escola foi modificada significantemente e o estudo foi ganhando proporções além do esperado. As dificuldades foram principalmente estruturais. A ausência do interesse dos professores das áreas científicas para envolverem-se na pesquisa foi o principal entrave. Há de se ressaltar que, à proporção que a pesquisa foi avançando, as alunas acabaram por contagiar os professores da área de Ciências, que passaram a adotar, mesmo que timidamente, atividades diferenciadas na sala de aula. Para o ano letivo seguinte, a direção da escola adotou para a Semana da Normalista, palestras e oficinas ministradas por professores convidados das áreas de Ciências. Destaca-se ainda que, entre as alunas, hoje formadas professoras, algumas já estão dando aula em escolas nos seus bairros, outras foram aprovadas em cursos superiores diversos, em universidades públicas e também em faculdades particulares com bolsas integrais.

Constatou-se que a avaliação é parte integrante do processo ensinoaprendizagem. Não há como se pensar em avaliação separada da atividade de ensino, pois ela é essencial para toda ação pedagógica. Ainda assim, destaca-se que há uma insistência no fazer pedagógico docente, desde a formação inicial, em separá-los.

No grupo dos conformados sobre isso, restam algumas opções. Permanecer exatamente do jeito que se está é uma delas. Manter o status quo do professor ou professora que detém o poder e a sapiência dos indicadores avaliativos expressos alguns. Os parâmetros válidos e legítimos do processo avaliativo serão aqueles que 
se preocupam essencialmente com os resultados. Os que se encaixam aqui, optam pela conformação pedagógica.

Uma vez conformados, consequentemente gera-se uma violência simbólica do papel professor-informador e aluno-receptor, que deforma o processo avaliativo e, por conseguinte, toda a ação de ensino-aprendizagem, reduzindo-os ao êxito ou fracasso demonstrado não só nos resultados, mas também no processo desqualificado de ensino. Aqui, a opção é por nos retirarmos do estágio de letargia e ficarmos imersos na deformação pedagógica, sendo deslocado o foco para o fracasso, e não para o sucesso escolar.

Por fim, ainda há a opção formativa da avaliação. Neste caso, principalmente quando se trata da área de ciências, historicamente com índice de interessados a cada ano menor (SALLA e RATIER, 2010), destaca-se que a avaliação atua como um dispositivo pedagógico essencial para a compreensão do processo de ensinoaprendizagem e do nó que se estabeleceu nessa área. Do ponto de vista da complexidade da própria essência do tema avaliação, não há como negar que esse estudo promoveu o repensar constante da prática de ensinar e avaliar. Diante do bojo teórico sobre avaliação, o caminho bibliográfico escolhido confirmou que é possível substituir no cotidiano escolar a concepção histórica tradicional de uma avaliação excludente, unilateral e punitiva.

Para estudos futuros, esta pesquisa apontou ainda para a possibilidade de continuidade voltada para a elaboração de portfólios digitais (ou virtuais) na área de Ensino de Ciências, de forma a contribuir na formação desses profissionais como um instrumento dinâmico e dialógico que promove a prática reflexiva, a autonomia e a criatividade no processo ensino-aprendizagem. Seu caráter interativo nos leva a crer que um "possível" portfólio virtual pode otimizar a formação continuada de docentes, a partir da construção do conhecimento científico num contexto favorável que se apresenta em condições de ser possível e bem-sucedido.

Sendo assim, poderíamos considerar que a avaliação integrada ao processo de ensino seja a resposta e a solução de todos os problemas na educação, mas não é (NASCIMENTO, 2015). Na verdade, a pretensão aqui é despertar a conscientização, reflexão e ação dos professores, pesquisadores da área e todos os que acreditam que é possível melhorar o ensino em ciências, desatando esse nó. Esse é o nó que se estabelece na avaliação, onde a genialidade pedagógica precisa encontrar espaço para práticas sensatas e eficazes no cotidiano das nossas aulas. E é nessa opção de formação que as fichas devem ser apostadas. 


\title{
The knot of the sciences evaluation: Forming, deforming or conforming?
}

\begin{abstract}
This study refers to a research developed with teachers-to-be in a school at Baixada Fluminense, in Rio de Janeiro. Assuming the evaluation practices in science education as a start point, we sought to understand the concept of evaluation of the study participants by using questionnaires and interviews; these were instruments to collect datas. This research was designed to be a qualitative study, assuming the "action-research" as the main methodology. The analysis highlights the node in the evaluation of science education and seeks to arouse awareness, reflection and action of teachers, the researchers and all who believe it is possible to improve the science education, from the initial training of teachers in high level, and combating deformation and / or conformation to untie this knot.
\end{abstract}

KEYWORDS: Learning evaluation. Science education. Teacher's education. Evalution by portfolio. 


\section{NOTAS}

1 No presente contexto, o conceito do termo "construtivistas" e suas derivações ao longo do texto é assumido na concepção de construtivismo abordado por Moreto (2008), onde o aluno tem papel ativo no processo e aprende à medida que responde aos incentivos do professor.

\section{REFERÊNCIAS}

BARDIN, L. Análise de conteúdo. Tradução: L. A. Reto, A. Pinheiro, 1a ed. São Paulo: Edições 70, 2011.

ESTEBAN, M. T. Avaliar: ato tecido pelas imprecisões do cotidiano. In: GARCIA, Regina Leite (org). Novos olhares sobre a alfabetização. São Paulo: Cortez, 2001.

Avaliação e fracasso escolar: questões para debate sobre a democratização da escola. Revista Lusófona de Educação. 2009, 13, 123-134.

GONZAGA, A.T. O Portfólio como estratégia de ensino-aprendizagem no ensino de ciências em um processo interdisciplinar com estudantes do 60 ano do Ensino Fundamental. Revista Amazônica de Ensino de Ciências. Rev. Areté. Manaus. v 6. N 10. P. 87-97. Jan-jun 2013.

HADJI, C. Avaliação desmistificada. Porto Alegre, ArtMed Editora, 2001.

HOFFMANN, J. Avaliação Mediadora; Uma Pratica da Construção da Pré-escola a Universidade. 17. ed. Porto Alegre: Mediação, 2000.

KRASILCHIK, M. Reformas e Realidades: o caso do ensino das ciências. São Paulo em Perspectiva 14 (1) 2000. p. 85 - 93

LEAL, C. A. Vamos brincar de quê?: Os jogos cooperativos no ensino de ciências. Orientadora Giselle Rôças. -- Nilópolis, RJ, 2013. 166f. il. 12 pranchas; 30 cm. Dissertação (Mestrado Profissional em Ensino de Ciências) - Programa de Pós Graduação em Ensino de Ciências, Instituto Federal de Educação, Ciência e Tecnologia do Rio de Janeiro. PROPEC, 2013.

LUCKESI, C. Avaliação da aprendizagem escolar. 14a Ed. São Paulo: Cortez, 2002. uma licenciatura em química. Revista Ciências e Ideias. N1. V1. Novembro Março 2009/2010. P. 69 - 75. 
MORAIS, M. B. ANDRADE, M. H. P. Ciências - ensinar e aprender. Belo Horizonte: Dimensão, 2009. 128p.

MORETO, V. P. Prova: um momento privilegiado de estudo, não um acerto de contas. 8. ed. Rio de Janeiro: Lamparina, 2008.

NASCIMENTO, L. Qual a medida da sua avaliação? Construindo um Portfólio de Avaliação no Ensino de Ciências. Orientadora: Profa..Drạ. Giselle Rôças. Nilópolis, RJ, 2015. 145 f. Dissertação (Mestrado Profissional em Ensino de Ciências). Programa de Pós-Graduação em Ensino de Ciências, Instituto Federal de Educação, Ciência e Tecnologia do Rio de Janeiro (IFRJ). PROPEC, 2015.

PALMA, R. C. B. MARTINS, J. B. Fracasso Escolar: novas e velhas perspectivas para um problema sempre presente. Pesquisa em Educação e Inserção Social. Univali, Itajaí, SC. ANPED Sul, 2008.

PINTO, R.O.ROCHA, M.S.P.M.L. A avaliação formativa: reflexões sobre o conceito no período de 1999 a 2009. Est. Aval. Educ., São Paulo, v 22, n 50, p.553-576, setdez 2011.

PERRENOUD, P. Avaliação: da excelência à regulação das aprendizagens - entre duas lógicas. Porto Alegre. Artmed, 1998.

POZO, J. I. CRESPO, M. A. G. A Aprendizagem e o Ensino de Ciências - do conhecimento cotidiano ao conhecimento científico. 5a Ed. Porto Alegre: Artmed, 2009.

RIO DE JANEIRO (Estado). Secretaria de Educação. Portaria SEEDUC/SUGEN no 419 de 27 de setembro de 2013. Estabelece normas de avaliação do desempenho escolar e dá outras providências. Diário Oficial do Poder Executivo do Estado do Rio de Janeiro, de 30 de setembro de 2013.

Resolução SEEDUC no 4951 de 04 de outubro de 2013. Fixa as matrizes curriculares da Educação Básica. Diário Oficial do Poder Executivo do Estado do Rio de Janeiro, outubro de 2013.

Currículo Mínimo: confira as orientações. SEEDUC/RJ. Disponível em: http://www.rj.gov.br/web/seeduc/exibeconteudo?article-id=759820. Acesso em: 01/03/2015. 
SACRISTÁN, J. G. O Currículo: Uma reflexão sobre a prática. Tradução por Ernani F. da Fonseca Rosa. Consultoria, supervisão e revisão técnica: Maria da Graça Sousa Horn. 3 ed. Porto alegre: Artes Médicas, 2000.

SALLA, F. e RATIER, R. Por que a docência não atrai. Revista Nova Escola. São Paulo: Ed. Abril, p. 8-11, jan./fev. 2010.

SOARES, M. Linguagem e escola: uma perspectiva social. 15 ed. São Paulo: Ática, 1997.

Letramento e alfabetização: as muitas facetas. Revista Brasileira de Educação. Jan /Fev /Mar /Abr 2004 no 25. 5 - 17.

ZABALA, A. A prática educativa: como ensinar. Porto Alegre: Artmed, 1998.

Recebido: 12 Mar. 2015

Aprovado: 20 jan. 2016

DOI: $10.3895 /$ rbect.v9n1.2820

Como citar:

NASCIMENTO, L. A. L.; RÔCAS, G. O nó da avaliacão em ciências: Formando, deformando ou

conformando? Revista Brasileira de Ensino de Ciência e Tecnologia, v. 9, n. 1, p. 354-379, jan./abr. 2016

Disponível em: <https://periodicos.utfpr.edu.br/rbect/article/view/2820>. Acesso em: xxx.

Correspondência:

Lucilene Aparecida e Lima do Nascimento

Rua Vera Lucia, 25. Rocha Sobrinho. Mesquita, CEP 26574-500, Rio de Janeiro.

Giselle Rôças

Rua Lucio Tavares, 1045, Centro, Nilópolis, Rio de Janeiro

Direito autoral: Este artigo está licenciado sob os termos da Licença Creative Commons-Atribuição 4.0

Internacional. 